\title{
UMA REVISÃO SOBRE A REFORMA DE ETANOL A VAPOR COM FOCO NA PRODUÇÃO DE HIDROGÊNIO
}

\author{
Ana Carolina Rodrigues Teixeira ${ }^{1 \mathrm{a}}$, Cristiano Henrique Gonçalves de Brito ${ }^{1 \mathrm{~b}}$, \\ Cristiana Brasil Maia ${ }^{1 \mathrm{c}}$, José Ricardo Sodré ${ }^{\mathrm{ld}}$, \\ 1Programa de Pós-Graduação em Engenharia Mecânica, Pontifícia Universidade \\ Católica de Minas Gerais, Av. Dom José Gaspar, 500, Belo Horizonte, 30535-901, BR \\ E-mails: aacrt88@ hotmail.com, ${ }^{b}$ cristianohbrito@gmail.com, ${ }^{c}$ cristiana@pucminas.br, \\ dricardo@pucminas.br
}

\section{RESUMO}

Atualmente a necessidade de reduzir as emissões de poluentes e obedecer às normas ambientais, principalmente no setor automotivo, tem contribuído para a busca de novas tecnologias mais eficientes e menos poluentes. As melhorias causadas nesse setor impactam diretamente o meio ambiente e a utilização de fontes energéticas. Nesse contexto, a busca por combustíveis alternativos, o hidrogênio é um combustível de queima limpa e que pode ser produzido a partir de fontes renováveis de energia, como o etanol, butanol e metanol. O etanol apresenta vantagens como o fácil manuseio, transporte, armazenamento, baixa toxidade e volatilidade, além ser facilmente obtido a partir de diferentes biomassas. A produção de hidrogênio a partir do etanol pode ser realizada a partir de diferentes técnicas, tais como a reforma a vapor, oxidação parcial (gaseificação) e a reforma autotérmica. Esse trabalho é direcionado para uma revisão de literatura da reforma a vapor de etanol, apresentando diversos estudos relacionados a essa área e a sua viabilidade.

\section{INTRODUÇÃO}

Recentemente a procura e a utilização de fontes renováveis de energia têm se intensificado, uma vez que contribuem, em geral, para a redução de impactos ambientais, destacando-se a poluição do ar em grandes centros urbanos. Com a crescente urbanização e industrialização há um aumento da demanda por transportes e, consequentemente, ocorre maior concentração de veículos nas cidades [1]. De acordo com o Balanço Energético Nacional divulgado por Brasil [2], o setor de transportes é responsável por 221,9 milhões de toneladas equivalentes de $\mathrm{CO}_{2}$, correspondendo a cerca de $46 \%$ das emissões antrópicas de $\mathrm{CO}_{2}$-eq associadas à matriz energética brasileira. As elevadas emissões de poluentes contribuem para intensificar problemas ambientais, tal como o agravamento do efeito estufa, além de ter impactos diretos na saúde da população, como é o caso de doenças respiratórias e cardiovasculares. Além disso, a legislação ambiental deve ser cumprida, o que é fonte de incentivo para o desenvolvimento de tecnologias que buscam a redução das emissões atmosféricas, como é o caso do uso do hidrogênio como combustível. 
O hidrogênio é um combustível de queima limpa que pode ser armazenado no estado líquido ou gasoso [3]. Em geral, a produção de hidrogênio a partir de combustíveis fósseis, tal como o petróleo, é mais comum. Entretanto, a busca pelo desenvolvimento sustentável e a tentativa de reduzir as emissões atmosféricas contribuíram para o crescimento dos estudos sobre a produção de hidrogênio a partir de fontes renováveis $[4,5]$. Combustíveis como o metanol, butanol e etanol têm sido utilizados na produção de hidrogênio, dos quais o etanol apresenta algumas vantagens, tais como: fácil manuseio, transporte, armazenamento e baixa toxidade e volatilidade. Além disso, o etanol pode ser facilmente obtido a partir de diferentes biomassas [6,7].

A produção de hidrogênio a partir do etanol pode ser realizada a partir de diferentes técnicas, tais como a reforma a vapor, oxidação parcial (gaseificação) e a reforma autotérmica. Nesse trabalho foram abordados estudos sobre a reforma a vapor no etanol, uma vez que ela é viável do ponto de vista termodinâmico [8] e econômico [9]. Dessa forma, o objetivo desse trabalho é realizar uma revisão bibliográfica sobre o reformador de etanol on-board e off-board.

\section{REFORMADOR DE ETANOL}

A reforma a vapor é um processo endotérmico em que o combustível reage com água na presença de catalisadores, responsáveis por aumentar a taxa de reações, resultando em uma mistura de gases contendo, em geral, hidrogênio $\left(\mathrm{H}_{2}\right)$, dióxido de carbono $\left(\mathrm{CO}_{2}\right)$, metano $\left(\mathrm{CH}_{4}\right)$, monóxido de carbono $(\mathrm{CO})$ e água $\left(\mathrm{H}_{2} \mathrm{O}\right)$ [10,11]. A eficiência de conversão está associada às propriedades físico-químicas do combustível, às condições ambientais, tais como pressão e temperatura, às condições técnicas do reformador e ao fluxo da mistura de combustível e vapor [12]. De acordo com Ahmed e Krumpelt [13], a eficiência teórica dos reformadores depende da razão atômica entre hidrogênio e carbono e do calor de reação de cada combustível. O etanol apresenta eficiência de conversão de 93,7\% e, de acordo com Brown [14], a faixa de temperatura ideal para a ocorrência da reforma a vapor é de $800 \mathrm{~K}$ a $1000 \mathrm{~K}$.

A produção de hidrogênio ocorre, basicamente, em duas etapas: reações de reforma do vapor (Steam Reforming Reactions - SRR), que ocorrem em temperaturas elevadas; e reações de troca água-gás (Water Gas Shift Reactions - WGSR), que ocorre em temperaturas baixas. A reação global da reforma a vapor do etanol é descrita abaixo [15]:

$$
\mathrm{C}_{2} \mathrm{H}_{5} \mathrm{OH}_{(v)}+\mathrm{H}_{2} \mathrm{O}_{(v)} \rightarrow 2 \mathrm{CO}_{2}+6 \mathrm{H}_{2}
$$

A reforma a vapor (SRR) ocorre através da equação:

$$
\mathrm{C}_{2} \mathrm{H}_{5} \mathrm{OH}_{(v)}+\mathrm{H}_{2} \mathrm{O}_{(v)} \rightarrow 2 \mathrm{CO}+4 \mathrm{H}_{2}
$$

A reação de troca água - gás (WGSR) ocorre através da equação:

$$
2 \mathrm{CO}_{(g)}+2 \mathrm{H}_{2} \mathrm{O}_{(v)} \rightarrow 2 \mathrm{CO}_{2}+2 \mathrm{H}_{2}
$$


É importante lembrar que algumas reações químicas podem ocorrer paralelamente durante o processo da reforma a vapor, tais como a formação de metano e carbono, que podem ser verificadas abaixo. Por isso, são necessários ajustes a fim de minimizar essas reações.

$$
\begin{gathered}
\text { Metanação: } \mathrm{CO}+3 \mathrm{H}_{2} \rightarrow \mathrm{CH}_{4}+\mathrm{H}_{2} \mathrm{O} \\
\text { Reação de Bouduard : } 2 \mathrm{CO} \rightarrow \mathrm{CO}_{2}+\mathrm{C}_{(\mathrm{s})}
\end{gathered}
$$

Os catalisadores são essenciais no processo de conversão de combustíveis líquidos e gasosos em hidrogênio, uma vez que são responsáveis por acelerar as reações químicas, e cada um apresenta diferentes formas de atuação. A escolha correta de um catalisador influencia diretamente na taxa de produção de hidrogênio e em aspectos ambientais e econômicos [16]. Diversos autores [17-20] investigaram catalisadores mais adequados para a reforma a vapor de etanol. O ródio $(\mathrm{Rh})$, o paládio $(\mathrm{Pd})$ e a platina $(\mathrm{Pt})$, comumente utilizados em catalisadores automotivos, foram avaliados em diversos suportes, tais como alumina e ceria/zircônia (Ce/Zr). Em geral, a Pt tem elevado custo, o que restringe o seu uso.

Um conceito que deve ser definido é a seletividade, que representa a relação entre o produto de uma reação e o reagente consumido. Isso é importante, pois é comum que o reagente do processo se combine em outras rotas químicas, formando produtos indesejáveis e contribuindo para que exista uma perda econômica, uma vez que nem todo o reagente utilizado se transformará no produto desejado. De acordo com Souza (2005), a seletividade do hidrogênio para a reação de reforma a vapor é decrescente na seguinte ordem: cobalto (Co), níquel $(\mathrm{Ni}), \mathrm{Rh}, \mathrm{Pt}$, rutênio $(\mathrm{Rt})$ e cobre $(\mathrm{Cu})$. Fatsikostas, Kondarides e Verykios [22] afirmam que o Ni é um metal não oneroso, suficientemente ativo e de grande área superficial, fazendo com que ele seja utilizado comumente.

De acordo com Contreras e outros [6], Frusteri e outros [19], Auprêtre e outros [17] e Diagne e outros [20], o Rh e o Ni são os catalisadores que apresentaram maior produção de hidrogênio a partir da reforma a vapor do etanol. A seleção do suporte é essencial e afeta diretamente as atividades dos catalisadores. Em relação ao $\mathrm{Rh}$ e ao $\mathrm{Ni}$, alguns suportes que têm sido mais estudados e promissores são os óxidos de magnésio, zinco, cério, lantânio e alumínio. Os autores concluíram que os catalisadores preparados com metais nobres ( $\mathrm{Rh}, \mathrm{Rt}$ e $\mathrm{Pd})$ e não nobres $(\mathrm{Ni}, \mathrm{Co}$ e $\mathrm{Cu})$ apresentaram seletividade superior a $90 \%$ e $80 \%$, respectivamente.

Moretti e outros [22] avaliaram o uso do óxido de (Ce/Zr) suportados em $\mathrm{Ni}$, Co e Ni/Co na produção de hidrogênio a partir da reforma a vapor de etanol. Os autores ressaltam a importância da interação metal-suporte para uma alta eficiência. Os resultados mostraram que o melhor suporte foi o misto de $\mathrm{Ni}$ e $\mathrm{Co}$, no que diz respeito à maior conversão do etanol e produção de hidrogênio, comparados aos suportes monometálicos. A eficiência de conversão do etanol chegou a $90 \%$, à temperatura de $500^{\circ} \mathrm{C}$.

Hou e outros [23] analisaram a produção de hidrogênio com o catalisador $\mathrm{Rh} / \mathrm{CeO}_{2}$. A Fig. 1 mostra a composição dos gases que saem do reformador de acordo com a temperatura do processo de reforma utilizando o catalisador $\mathrm{Rh} / \mathrm{CeO}_{2}$. A formação de acetaldeídos e acetona não foi observada em nenhuma temperatura, o que indica alta eficiência de conversão do catalisador. $\mathrm{O}$ aumento da temperatura proporciona uma 
elevação da concentração de hidrogênio e, paralelamente, a redução das concentrações de $\mathrm{CO}_{2}$ e $\mathrm{CH}_{4}$.

Figura 1 - Efeito da temperatura nos gases que saem do reformador.

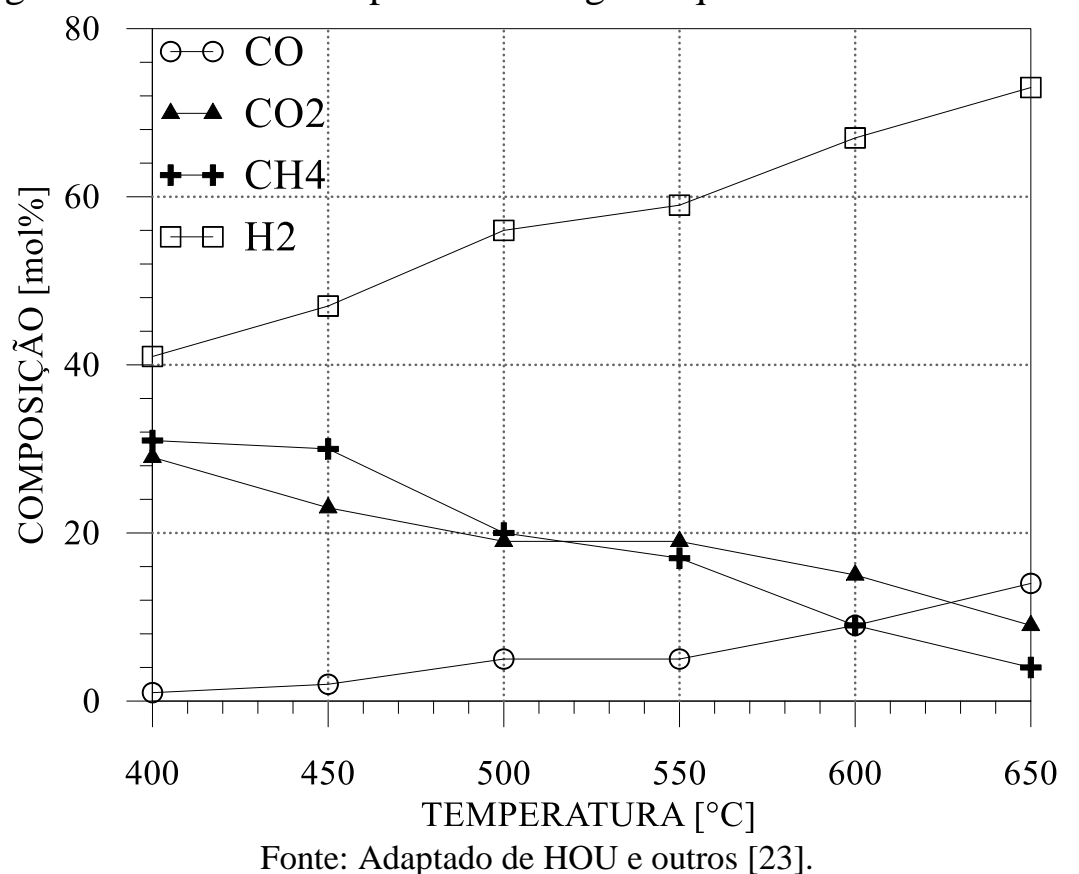

\section{ABORDAGENS}

\subsection{Experimental}

Souza [12] analisou técnica e economicamente um reformador de etanol para produzir $0,7 \mathrm{Nm}^{3} / \mathrm{h}$ de hidrogênio a fim de abastecer uma célula de combustível de $1 \mathrm{~kW}$. A análise técnica mostrou que as melhores condições para a reforma a vapor do etanol são com temperaturas superiores a, aproximadamente, $400^{\circ} \mathrm{C}$ a pressão atmosférica de $1 \mathrm{~atm}$. É sugerida a faixa entre $600^{\circ} \mathrm{C}$ e $700^{\circ} \mathrm{C}$, uma vez que acima dessa faixa a eficiência do processo tende a se estabilizar e os custos se elevam.

Silva [24] desenvolveu dois protótipos de reformador a vapor de etanol para abastecer uma célula a combustível de $1 \mathrm{~kW}$, e analisou os parâmetros termoquímicos associados a esse processo. Para o reformador foi utilizado um catalisador de $\mathrm{NiCu}$ baseado em $\gamma$ $\mathrm{Al}_{2} \mathrm{O}_{3}$, com temperatura de reação de $923 \mathrm{~K}$ e pressão de $0,101 \mathrm{MPa}$. No reator de alternância, o catalisador utilizado foi o $\mathrm{CuZnO}$ baseado em $\gamma-\mathrm{Al}_{2} \mathrm{O}_{3}$, com temperatura de reação de $493 \mathrm{~K}$ e pressão de $0,101 \mathrm{MPa}$. Os gases foram analisados através do método de cromatografia gasosa. Para a produção de $0,7 \mathrm{Nm}^{3} / \mathrm{h}$ de hidrogênio, foi necessária uma vazão de etanol de, aproximadamente, $0,11 \mathrm{~m}^{3} / \mathrm{h}$.

Barbosa [25] avaliou o processo de reforma a vapor a partir da preparação de catalisadores de cobre, níquel e cobre/níquel suportados em óxido de zinco. Os ensaios foram realizados com temperaturas entre $300^{\circ} \mathrm{C}$ e $650^{\circ} \mathrm{C}$, razão molar água/etanol de 3:1 e 6:1. Os resultados mostraram uma concentração de $80 \%$ de hidrogênio nos gases que saem do reformador para todas as temperaturas estudadas. A autora concluiu que a melhor faixa de temperatura para a produção de hidrogênio é de $450^{\circ} \mathrm{C}$ a $550^{\circ} \mathrm{C}$. 
Tsolakis e Megaritis [26] realizaram um estudo experimental do processo de reforma de óleo diesel, considerando diferentes cenários de pressão e rotação, a fim de reduzir as emissões de fumaça e $\mathrm{NO}_{\mathrm{X}}$ de um motor diesel operando com EGR. O reformador foi alimentado com o gás de exaustão, óleo diesel e água nas respectivas vazões: 8 litros $/ \mathrm{min}$, $30 \mathrm{ml} / \mathrm{h}$ e $15-60 \mathrm{~m} / \mathrm{h}$. Os produtos formados pelo processo de reforma continham três principais componentes: hidrogênio, monóxido de carbono e hidrocarbonetos não queimados, sendo a máxima concentração de hidrogênio encontrada $22 \%$. Os resultados mostraram reduções de fumaça, $\mathrm{NO}_{\mathrm{X}}$ e consumo de combustível, além de melhorar a eficiência do motor. Entretanto, os autores ressaltam que, para um aumento da concentração de hidrogênio produzido, é necessário um segundo reator capaz de promover a reação entre o monóxido de carbono e a água, produzindo dióxido de carbono e hidrogênio.

Li et al. [27] desenvolveram um estudo sobre um reformador a vapor de etanol embarcado para avaliar o seu desempenho em relação à taxa de eficiência de conversão do etanol hidratado, além de otimizar os parâmetros do motor e verificar a real viabilidade de sua utilização. Os resultados mostraram que a conversão do HE75 (75\% hidratado-etanol) atinge um valor máximo a uma temperatura cerca de $675 \mathrm{~K}$. Os efeitos da taxa de fluxo e temperatura na distribuição do produto são mínimos. Em comparação com o protótipo de motores a gasolina, as diminuições médias do consumo específico de combustível, emissões de $\mathrm{NO}_{\mathrm{X}}$, emissão de $\mathrm{CO}$ e as emissões de hidrocarbonetos totais para o motor otimizado foram de $6 \%, 70 \%, 50 \%$ e $80 \%$, respectivamente. Além disso, os resultados mostraram que o aumento da razão de compressão e a combustão a partir de uma mistura pobre representam uma oportunidade promissora para a utilização do etanol hidratado.

\subsection{Numérico}

Tartakovsky et al. [28] avaliaram o desempenho de um motor com ignição por centelha alimentado pelos produtos da reforma a vapor de etanol através da simulação do reformador de etanol acoplado ao motor, que pode ser observado no esquema apresentado na Fig. 2. A maior eficiência de conversão do sistema alcançada foi $59 \%$, verificada com a temperatura da reforma de $1100 \mathrm{~K}$. As maiores reduções de $\mathrm{CO}$ foram obtidas com a relação água/etanol de 1,2 e 1,8. Com os produtos da reforma abastecendo o motor foi possível melhorar a sua eficiência térmica para $40 \%$, que era de $34 \%$ para operação com gasolina e 36\% com etanol. As emissões de $\mathrm{CO}$ foram reduzidas de 3,5 e 10 vezes, quando comparada com etanol e gasolina, respectivamente. As emissões de $\mathrm{NO}_{\mathrm{X}}$ foram reduzidas cerca de 4 vezes em comparação com o motor abastecido apenas com gasolina para a temperatura de reforma de $1000 \mathrm{~K}$ e relação água/etanol de 1,8 .

Figura 2 - Esquema do sistema de reforma acoplado ao motor.

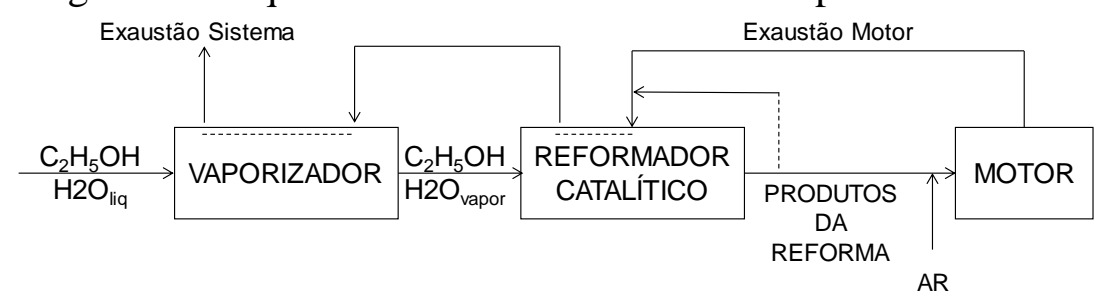

Fonte: Adaptado de Tartakovsky et al.

Uriz e outros [29] apresentaram um estudo numérico da reforma a vapor de etanol modelando o catalisador como um reator de micros canais. Para a simulação numérica 
tridimensional os autores utilizaram o ANSYS CFX, onde foram implementadas a cinética química das reações químicas sobre o material catalítico $\mathrm{Co}_{3} \mathrm{O}_{4}-\mathrm{ZnO}$. No estudo foram avaliados os efeitos das dimensões características dos micros canais, da carga de catalisador, da velocidade do escoamento e da quantidade de calor fornecido ao processo no desempenho do reator. O modelo consiste de canais paralelos de seção quadrada, com $20 \mathrm{~mm}$ de comprimento e largura de $0,10 \mathrm{~mm}, 0,35 \mathrm{~mm}$ e $0,70 \mathrm{~mm}$ em cada um dos casos avaliados. A deposição de material catalítico foi considerada uniforme ao longo da superfície, tendo sido simulado casos com 1,2 e $4 \mathrm{mg} / \mathrm{cm}^{2}$. A velocidade espacial horária do gás (GHSV) variou de $5.250 \mathrm{~cm} / \mathrm{h}$ a $70.000 \mathrm{~cm} / \mathrm{h}$. As simulações foram realizadas ainda com a entrada de calor variando entre $250 \mathrm{MJ} / \mathrm{mol}$ e $375 \mathrm{MJ} / \mathrm{mol}$ de etanol. Eles verificaram que a conversão do etanol e a temperatura na saída do reator é sensivelmente alterada pela entrada de calor e aumenta com o aumento desse parâmetro. Os autores observaram que a velocidade espacial horária do gás afeta significativamente a produção de hidrogênio. Na condição mais favorável, foram obtidos $75 \%$ de hidrogênio para GHSV de $5250 \mathrm{~cm} / \mathrm{h}$ e $60 \%$ de hidrogênio para GHSV de $70.000 \mathrm{~cm} / \mathrm{h}$. Verificou-se que o aumento da quantidade de material catalítico é a melhor abordagem para altos valores de GHSV. Para GHSV de $70.000 \mathrm{~cm} / \mathrm{h}$ a produção de hidrogênio foi ampliada de $57 \%$ para $63 \%$ ao aumentar a quantidade de material catalítico de $1 \mathrm{mg} / \mathrm{cm}^{2}$ para $4 \mathrm{mg} / \mathrm{cm}^{2}$. Para as dimensões dos micros canais, os autores verificaram que as menores dimensões $(0,10 \mathrm{~mm}$ e $0,35 \mathrm{~mm}$ ) resultaram em modelos que garantiram uma temperatura de escoamento mais uniforme, favorecendo a produção de hidrogênio por não dissipar energia térmica ao longo do escoamento.

Figura 3 - Resultados para (A) conversão do etanol e temperatura de conversão para diferentes valores de calor adicionado ao processo e (B) produção de hidrogênio
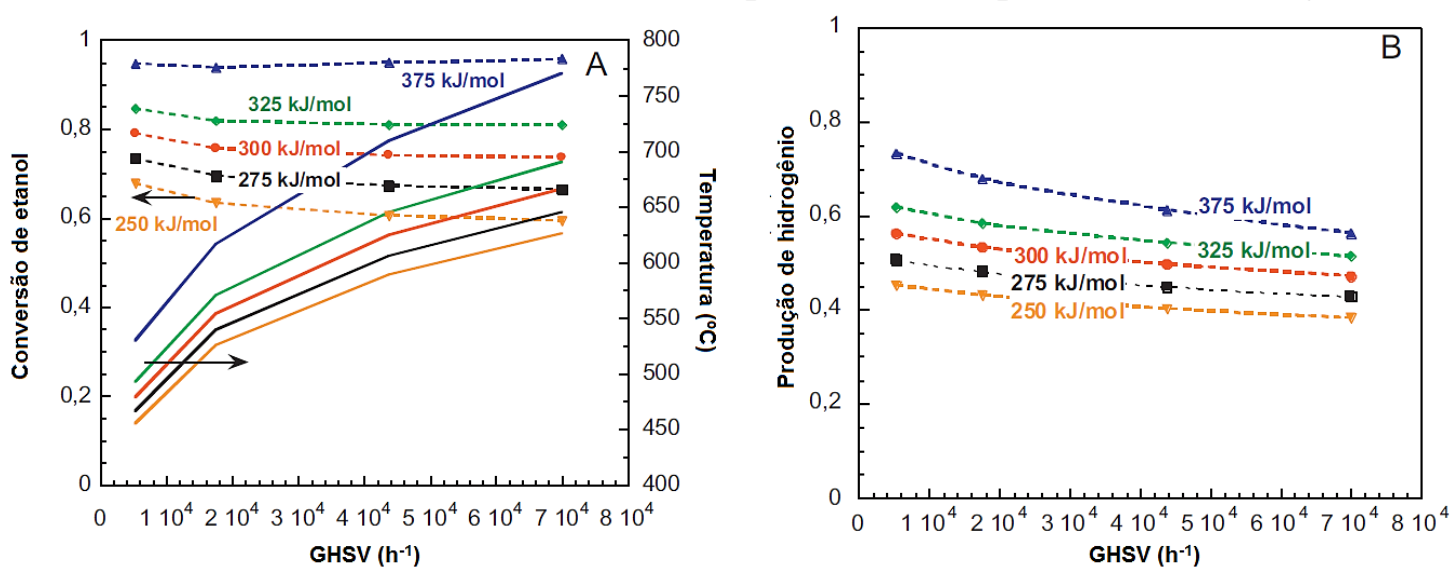

Fonte: Adaptado de Uriz e outros [29].

Wu e outros [30] fizeram um estudo numérico para avaliar o aumento da sorção no processo de reforma a vapor de etanol em catalisador com materiais multifuncionais $\mathrm{NiMgAl}$. Os autores utilizaram o programa gPROMS, baseado no Método dos Elementos Finitos (FEM), para a solução das equações que descrevem o modelo. Os autores verificaram que a sorção é potencializada na região de reação quando a razão material catalítico disponível e vazão molar de etanol aumenta, especialmente quando se encontra na faixa de 0,15 a $0,25 \mathrm{~kg} \cdot \mathrm{h} \cdot \mathrm{mol}^{-1}$. Eles verificaram que o material multifuncional $\mathrm{NiMgAl}$ possui tal como esperado propriedades bivalentes, catalítica e seletiva do dióxido de carbono e o modelo proposto previu adequadamente a reação de reforma do etanol e a adsorção do $\mathrm{CO}_{2}$. Verificaram ainda que a condição ótima de operação é obtida quando a razão vapor-etanol, $\mathrm{R}_{\mathrm{E} / \mathrm{S}}=10$, a razão material catalítico e fluxo molar de etanol, 
$\mathrm{m}_{\text {cat }} \cdot \mathrm{V}_{\text {etanol }}=0,25 \mathrm{~kg} \cdot \mathrm{h} \cdot \mathrm{mol}^{-1}$ e temperatura de reação a $773 \mathrm{~K}$. Nesta condição o aumento de desempenho é significativo, obtendo hidrogênio com pureza superior a $99 \%$ na condição de reação com sorção melhorada.

Wu e outros [31] realizaram a simulação bidimensional de um reator adsortivo para avaliar seu desempenho no processo de reforma a vapor de etanol. O modelo matemático proposto pelos autores considerou axi-simetria, considerando área da seção transversal, porosidade e massa específica do reator constantes ao longo do comprimento. As equações descritivas do fenômeno foram resolvidas no programa gPROMS a partir do FEM. O reator adsortivo adotado é composto por material multifuncional $\mathrm{K}-\mathrm{Ni}-\mathrm{Cu}-\mathrm{HTlc}$, onde $\mathrm{Ni}-\mathrm{Cu}$ compõe o material catalítico, e o suporte catalítico é por potássio $(\mathrm{K})$ e hidrotalcita, que formam o adsorvente de $\mathrm{CO}_{2}$. Os autores desenvolveram as simulações nas seguintes condições: $\mathrm{T}=773 \mathrm{~K}, \mathrm{P}=101 \mathrm{kPa}, \mathrm{R}_{\mathrm{V} / \mathrm{E}} 5$ e diferentes vazões mássicas de vapor-etanol. A Fig. 3 apresenta os resultados obtidos para a composição do efluente. As linhas cheias representam os dados numéricos e os pontos presentam os dados experimentais utilizados na validação do modelo. Os autores verificaram que o processo de reforma pode ser divido em três estágios. O primeiro é o estágio denominado préavanço, em que o efluente do processo possui pureza $>99 \%$ de $\mathrm{H}_{2}$ e apenas contém no máximo $30 \mathrm{ppm}$ de $\mathrm{CO}$. Em seguida vem o estágio denominado avanço, em que a composição do efluente é alterada drasticamente ao longo do tempo e a pureza do efluente é reduzida. O último estágio, denominado pós-avanço, é obtido após atingir a saturação de $\mathrm{CO}_{2}$ no reator, o que melhora a sorção do reator e mantem a composição do efluente constante.

Figura 3 - Composição do efluente ao longo do tempo para o reator operando sob a vazão mássica de (a) $4 \times 10^{-5} \mathrm{~mol} \cdot \mathrm{s}^{-1}$ e (b) $8 \times 10^{-5} \mathrm{~mol} \cdot \mathrm{s}^{-1}$. Condições de operação: $\mathrm{T}=$ $773 \mathrm{~K}, \mathrm{P}=101 \mathrm{kPa}$ e $\mathrm{R}_{\mathrm{V} / \mathrm{E}}=5$. Pontos e linhas correspondem a dados experimentais e numéricos respectivamente.
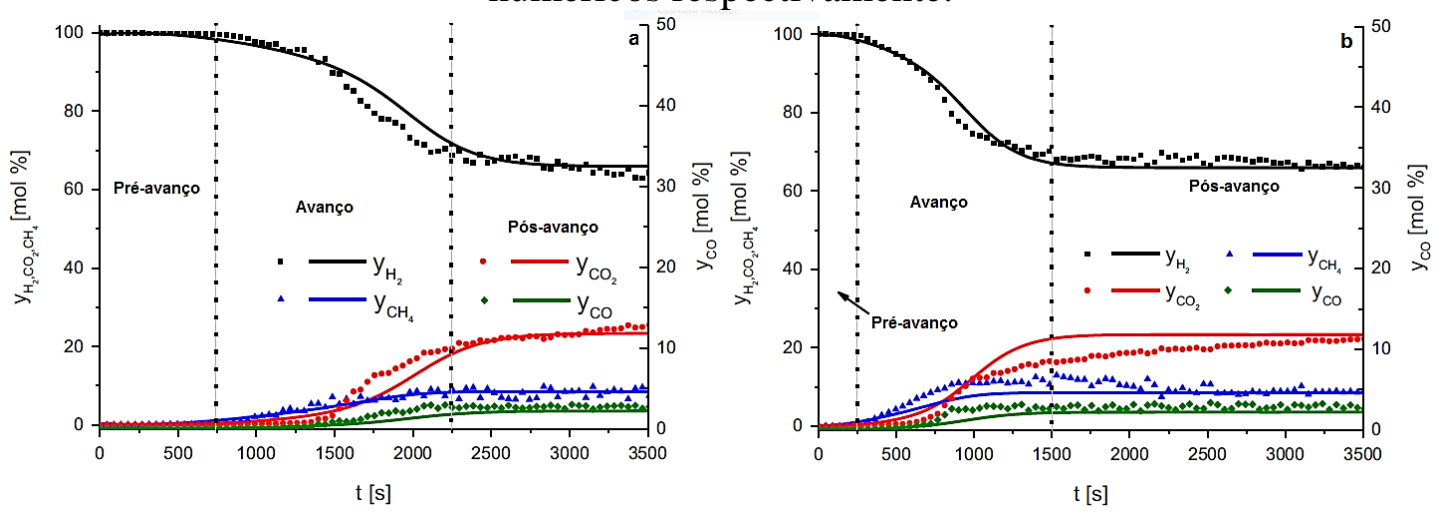

Fonte: Adaptado de Wu e outros [31].

\section{CONCLUSÃO}

O presente trabalho foi desenvolvido com o objetivo de avaliar a reforma a vapor de etanol e algumas aplicações em motores de combustão interna. A partir dos estudos analisados, foi possível observar alguns parâmetros importantes responsáveis pelo sucesso da formação de hidrogênio a partir da reforma a vapor, tais como a temperatura da reforma, o tipo de catalisador e a pressão. Esta última interfere diretamente no grau de avanço da reação global, e assim, na produção de hidrogênio. Os estudos mostraram que 
a temperatura adequada para a reforma do etanol deve ser superior a $500^{\circ} \mathrm{C}$ e a pressão de $1 \mathrm{~atm}$. Os catalisadores são elementos-chave na conversão de combustíveis líquidos e gasosos em hidrogênio; assim, a escolha do catalisador adequado é de extrema importância. Os catalisadores que apresentaram melhores eficiências de conversão foram os que contém níquel e ródio. Além disso, o combustível utilizado na reforma a vapor, que no caso desse trabalho foi o etanol, deve ser escolhido com cautela, pois deve apresentar alta eficiência, custo-benefício, segurança e fácil disponibilidade.

\section{REFERÊNCIAS}

[1] SALVI, B.L.; SUBRAMANIAN, K.A; PANWAR, N.L. Alternative fuels for transportation vehicles: A techicnal review. Renewable and Sustainable Energy Reviews, v. 25, p. 404-419, 2013.

[2] BRASIL. Balanço Energético Nacional, 2015 Disponível em: <https://ben.epe. gov.br/downloads/S\%C3\%ADntese\%20do\%20Relat\%C3\%B3rio\%20Final_2015_Web. pdf>. Acesso em: 29 jun. 2015.

[3] ARMOR, J. Striving for catalytically green processes in the 21st century. Applied Catalysis A: General, v. 182, n. 2, p. 153-162, 1999.

[4] NI, M.; LEUNG, D.Y.C.; LEUNG, M.K.H. A review on reforming bio-ethanol for hydrogen production, International Journal of Hydrogen Energy, v. 32, p. 3238 - 3247, 2007.

[5] CHATTANTHAN, S.A.; ADHIKARI, S.; ABDOULMOUMINE, N. A review on current status of hydrogen production from bio-oil, Renewable Sustainable Energy Reviews, v. 16, p. 2366-2372, 2012.

[6] CONTRERAS, J.L.; SALMONES, J.; COLÍN-LUNA, J.A.; NUÑO, L.; QUINTANA, B.; CÓRDOVA, I.C.; ZEIFERT, B.; TAPIA, C.; FUENTES, G.A. Catalysts for $\mathrm{H} 2$ production using the ethanol steam reforming (a review), International Journal of Hydrogen Energy, v. 39, p. 18835-18853, 2014.

[7] LLORCA, J.; HOMS, N.; SALES, J.; RAMÍREZ, P. Efficient production of hydrogen over supported Co catalysts from ethanol steam reforming, Journal of Catalysis, v. 209, p. 306-317, 2002.

[8] VAIDYA, P.D.; RODRIGUES, A.E. Insight into steam reforming of ethanol to produce hydrogen for fuel cells. Chemical Engineering Journal, v. 17, p. 39-49, 2006.

[9] HARYANTO, A.; FERNANDO, S.; MURALI, N.; ADHIKARI, S. Current status of hydrogen production techniques by steam reforming ethanol: a review, Energy \& Fuels, v. 19, p. 2098-2106, 2005.

[10] STEINBERG, M. The Hy-C process (thermal decomposition of natural gas) potentially the lowest cost source of hydrogen with the least $\mathrm{CO} 2$ emission, Fuel and Energy Abstracts, v. 37, p. 182, 1996.

[11] POIRIER, M. G.; SAPUNDZHIEV, C. Catalytic decomposition of natural gas to 
hydrogen for fuel cell applications, International Journal of Hydrogen Energy, v 22, p. 429-433, 1997.

[12] SOUZA, A.C.C. Análise técnica e econômica de um reformador de etanol para produção de hidrogênio, 2005. 138 p. Dissertação - Universidade Estadual Paulista, Faculdade de Engenharia de Guaratinguetá, Guaratinguetá.

[13] AHMED, S.; KRUMPELT, M. Hydrogen from hydrocarbon fuels for fuel cells. International Journal of Hydrogen Energy, v. 26, p. 291-301, 2001.

[14] BROWN, L.F. A comparative study of fuels for on-board hydrogen production for fuel-cell-powered automobiles. International Journal Hydrogen Energy, v. 26, p. 381397, 2001.

[15] FRENI, S.; MAGGIO, G.; CAVALLARO, S. Ethanol steam reforming in a molten carbonate fuel cell: a thermodynamic approach. Journal of Power Sources, v. 62, p. 6773, 1996.

[16] NI, M.; LEUNG, D.Y.C.; LEUNG, M.K.H. A review on reforming bio-ethanol for hydrogen production, International Journal of Hydrogen Energy, v. 32, p. 3238 - 3247, 2007.

[17] AUPRÊTE, F. et al. Bio-ethanol catalytic steam reforming over supported metal catalysts. Catalysis Communications, n. 3, v. 6, p. 263-267, 2002.

[18] ERDOHELYI, A. Hydrogen formation in ethanol reforming on supported noble metal catalysts, Catalysis Today, v. 116, p. 367-376, 2006.

[19] FRUSTERI, F., et al. $\mathrm{H}_{2}$ production for $\mathrm{MC}$ fuel cell by steam reforming of ethanol over $\mathrm{MgO}$ supported $\mathrm{Pd}, \mathrm{Rh}, \mathrm{Ni}$ and Co catalysts. Catalysis Communications, n. 5, v. 10, p. 611-615, 2004.

[20] DIAGNE, C. et al. Efficient hydrogen production by ethanol reforming over Rh catalysts. Effect of addition of $\mathrm{Zr}$ on $\mathrm{CeO} 2$ for the oxidation of $\mathrm{CO}$ to $\mathrm{CO} 2$. Sustainable Hydrogen Production by Catalytic Bio-Ethanol Steam Reforming, n. 7, p. 617-622, 2004.

[21] FATSIKOATAS, A.; KONDARIDES, D.; VERYKIOS, X. Production of hydrogen for fuel cells by reformation of biomass-derived ethanol, Catalysis Today, v.75, p. 145$155,2002$.

[22] MORETTI, E.; STORARO, L.; TALON, A.; CHITSAZAN, S.; GARBARINO, G.; BUSCA, G.; FINOCCHIO. Ceria-zirconia based catalysts for ethanol steam reforming, Fuel, v. 153, p. 166-175, 2015.

[23] HOU, T.; YU, B.; ZHANG, S.; XU, T.; WANG, D.; CAI, W. Hydrogen production from ethanol steam reforming over $\mathrm{Rh} / \mathrm{CeO} 2$ catalyst, Catalysis Communications, v. 58 , p. 137-140, 2015.

[24] SILVA, M. E. Análise termoquímica de reformador de etanol: Produção de hidrogênio para acionamento de uma célula a combustível do tipo PEM de 1 kW, 2005. 
110 p. Dissertação - Universidade Estadual Paulista, Faculdade de Engenharia de Guaratinguetá, Guaratinguetá.

[25] BARBOSA, E.F. Reforma a vapor do etanol sobre catalisadores $\mathrm{Cu}-\mathrm{Ni} / \mathrm{ZnO}, 2008$. 130 p. Universidade Federal de São Carlos, Programa de Pós-Graduação em Engenharia Química, São Carlos.

[26] TSOLAKIS, A.; MEGARITIS, A. Exhaust gas fuel reforming for Diesel engines A way to reduce smoke and NOx emissions simultaneously, SAE Technical Paper 200401-1844, 2004, doi:10.4271/2004-01-1844.

[27] LI, G. et al. A novel strategy for hydrous-ethanol utilization: Demonstration of a spark-ignition engine fueled with hydrogen-rich fuel from an onboard ethanol/steam reformer, International Journal of Hydrogen Energy, v. 38, p. 5936-5948, 2013.

[28] TARTAKOVSKY, L. et al. Performance Analysis of SI Engine Fueled by Ethanol Steam Reforming Products, SAE Technical Paper 2011-01-1992, 2011, doi: 10.4271/2011-01-1992.

[29] URIZ, I. et al. Computational fluid dynamics simulation of ethanol steam reforming in catalytic wall microchannels, Chemical Engineering Journal, v. 167, 603-609, 2011.

[30] WU, I.-J. et al. Sorption-enhanced steam reforming of ethanol on $\mathrm{NiMgAl}$ multifunctional materials: Experimental and numerical investigation, Chemical Engineering Journal, v. 231, p. 36-48, 2013.

[31] WU, I.-J. et al. Sorption-enhanced steam reforming of ethanol for continuous highpurity hydrogen production: 2D adsorptive reactor dynamics and process design, Chemical Engineering Science, v.118, p. 83-93, 2014. 